\title{
DDS Profile: Deborah D. Proctor, MD
}

\author{
Deborah D. Proctor ${ }^{1}$
}

Accepted: 13 April 2021 / Published online: 2 July 2021

(C) The Author(s), under exclusive licence to Springer Science+Business Media, LLC, part of Springer Nature 2021

\section{Find Something That Inspires You}

"First, find something that inspires you; second, find something that will pay you." I initially shared this piece of advice with my two sons when they were still young. I believe it is extremely important that you find your life's passion in that order and not the other way around. If you love what you do, it is not work; if you get paid to do what you love doing that is a true treasure.

I began as a general physician and over the subsequent 40 years have narrowed my focus to manage a limited set of patients, e.g., those who have inflammatory bowel disease (IBD). I changed careers at least twice, adhering to the belief that if I were not enjoying what I was doing, it was time to do something else. In addition to the guidance I gave my sons, the advice I live by is to not be afraid to change. Mix it up, keep things interesting. Here is my story.

At the University of Cincinnati College of Medicine, I wanted to be a pediatrician, so I matched into a pediatric residency in Norfolk, Virginia in 1982. Meanwhile, the U.S. Navy had paid for my medical schooling, and, although willing to let me train outside of a Navy residency, after one year, they wanted me to practice in the Navy as a general medical officer. I spent the next four years in the Virginia Beach area at three separate U.S. Navy clinics. My first overnight duty call was solo with a physician's assistant, albeit an experienced one. After having spent the last year-my pediatric internship-doing four months in the newborn nursery, four months in the neonatal intensive care unit, and four months on an inpatient pediatric floor, in walked a 50-year-old man who was having a myocardial infarction. During eight of the previous 12 months, I had not cared for any human being older than six months. Fortunately, I

Deborah D. Proctor

deborah.proctor@yale.edu

1 Department of Internal Medicine, Section of Digestive Diseases, Yale Inflammatory Bowel Disease Center, Yale University School of Medicine, 40 Temple Street, Suite 1A, New Haven, CT 06510, USA remembered I could call 911 for help. As the subsequent four years went by, I formed life-long friendships, grew into being a physician, and spent time reflecting on what I wanted to do for the "rest of my life." It was not taking care of children. I loved taking care of adults. When it came time to reapply for residency, I decided to repeat my internship, this time in Internal Medicine (IM) at Beth Israel (BI) Hospital in Boston.

My three years at the BI were transforming in my growth as a person and a physician-all along the way I was pleased with my decision to change from pediatrics to IM. Now I needed to decide if I wanted to do a subspecialty fellowship or stay in general IM. By the summer of my second year of residency-remember in the late 1980s, we applied for fellowship at the beginning of our second year-I had narrowed my decision down to three possible areas-gastroenterology (GI), rheumatology, and infectious disease. I had my no-call rheumatology elective coming up and was driving back from the VA hospital to our main BI hospital after having been up all night, when one of my fellow residents called and asked me if he could change his GI call elective for my rheumatology no-call elective. I agreed, as long as I could do my "no-call elective" later in the year.

I fell in love with GI. I had wonderful mentors-Stuart Spechler, Sanjiv Chopra, and Raj Goyal, to name a fewover the next three weeks and decided then and there that GI was for me. I wanted to stay at the BI for my GI fellowship and felt fortunate when I was selected. I was the first female GI fellow hired by my home institution. I should also make note that in 1990, about $12 \%$ of U.S. gastroenterologists were women. Side note- this is something I could never figure out - then and now I feel that this is the best job in the world. I get to play video games all day long and get paid to do so. Add in that the diseases are so rich and fascinating, and this is truly fun! I was following the advice I would give my sons in future years.

During my GI fellowship, I met my husband, Rob, and we were married. I graduated from my GI fellowship program in 1992. To place this in historical context, Bill Clinton had just been elected president, and health care reform was 
undergoing massive changes. In regard to subspecialties, plans were to make primary care medicine more profitable and decrease the need for subspecialists. Few academic universities were hiring, and the only GI academic job in the Boston area was 50\% GI/50\% IM. I was recruited to East Carolina University (ECU) in Greenville, NC as a full-time $100 \%$ GI academician.

Rob and I moved to Greenville and stayed for the next six years. During those years, I was a true general gastroenterologist. I did everything-liver biopsies, ERCPs, and managing luminal diseases, including IBD. Although Mark Peppercorn had been an important influence on my education at the BI and I felt confident in my ability to take care of patients with IBD, in the 1990s we only had mesalamine, prednisone, and mercaptopurine/azathioprine to treat our patients. A general gastroenterologist could treat IBD patients. It would not be until 1999-2000 before we had our first biologic, the anti-tumor necrosis factor antibody, infliximab, for our patients with Crohn's disease. During our six years at ECU, we had our two sons, and I moved up the administrative ladder taking over as Section Chief during my last two years at ECU.

In 1998, Yale was recruiting a clinician educator, and my family and I were interested in moving closer to our extended families. I was the first clinician educator, a new role, hired from outside of Yale. I was also only the third woman hired into the Section of Digestive Diseases; Rosemarie Fisher and Guadalupe Garcia-Tsao were already successful women gastroenterologists at Yale when I arrived.

To say I was impressed with my future colleagues at Yale is a massive understatement. My initial observation has held true over the $20+$ years that I have been a faculty member here. My second piece of advice to my sons was to make sure you surrounded yourself with colleagues who are smarter than you are-you will always rise to the level of those around you. In addition to the amazing accomplishments of my Yale colleagues, I appreciated the collegiality among them. There was a true desire to help each other. As faculty helped each other rise up, we all rose together. This has also remained true.

When I arrived at Yale, our two sons were almost four and barely one year old, respectively. Fortunately, we had a nanny who came with us from North Carolina and stayed with us for the next six years. An aside and a word of advice to the reader-hire good people to look after your children.

Once again I was recruited to be a general gastroenterologist, and I saw patients with all types of GI diseases. At one point, I was the inpatient attending for all three services at Yale-New Haven Hospital. It was busy but doable.

Slowly, I started to peel the layers of the onion back. I could see the writing on the wall. Although my section needed a clinical gastroenterologist to see general GI patients, in order to be promoted I would need to develop a niche within GI. By this time, I was seeing more and more patients with IBD and enjoying caring for them, so I decided to focus on this disease and hand over my liver patients and ERCPs to my colleagues who were better at managing these patients than I was. This was an alteration in my career and one I needed to make if I wanted to continue at Yale. I chose a disease process I enjoyed managing and developed this avenue.

In 1999-2000, infliximab was approved for use in patients with Crohn's disease. The first patient I treated with infliximab had horrible perianal disease that was cleared up after one infusion. I remember patients coming in to see me and not wanting to sit down because of the pain. We soon needed to add chairs to our waiting room because these same patients were responding so well to infliximab that they could now sit down. What a wonderful thing this was!

I have truly enjoyed living through history with the development of biologics for patients with IBD. As another side note, living through history is an interesting experience. When it is happening, time appears to go slowly, but when the experience is reflected upon, it actually seems to have whizzed by.

Because we were all new at treating IBD patients with biologics, we needed to learn how and when to use them, monitor drug levels, combine drugs, manage drug side effects, and understand surgical options. What was best for a patient two or three years ago might not be the best treatment for a patient now. We set up case conferences; things were happening so fast it was often difficult to keep up. What worked for one patient could also work for another, so we shared our experiences and wisdom.

As we understood more about the immunology of IBD, the pieces of the puzzle started to fall into place. Soon there would be other biologics; we would gain knowledge about the importance of the underlying genetics and learn about all-important intestinal microbiome.

I knew that caring for complex chronically ill patients would require a team effort, so I formed our IBD Program at Yale in 2005. This was an administrative challenge and one that I am still working on. We started off as a multidisciplinary team; personnel came and went; and now for the past several years, our program has been growing by leaps and bounds.

Early on I felt it was important to get involved with others in our field, and I chose the American Gastroenterological Association (AGA). I have attended every Digestive Disease Week since I was a GI fellow. Each year I would make a point of meeting at least three new people. Before long, I had met hundreds of other gastroenterologists. I served on AGA committees as well as on the AGA Governing Board. And a few years ago, I was honored to receive the highest education award that the AGA bestows on a member, the Distinguished Educator Award. 
This brings me to the other half of my professional career-education. In tandem with my IBD clinical career, I loved teaching, mentoring, and being involved with trainees. I have always believed that the best teachers are those we do not even know are teaching us. At ECU, I had started a GI fellowship, and after a few years of my arrival at Yale I became the GI Fellowship Program Director (PD). As PD I did fun things, including working with my GI colleagues around the country and with Alvin Roth, the 2012 Nobel Laureate in Economic Sciences, as well as others outside of GI, to reinstate our Fellowship Match in 2005. Of all the things I have done over the years, getting the match up and running again after it had fallen apart, is one of the things I am proudest of.

My story would not be complete without stressing the importance of activities outside of work. My husband and I were very involved with our sons' lives, including coaching their Odyssey of the Mind team for several years, coaching sports, and judging and writing for Science Olympiad. I have written about my volunteer work in Honduras [1], which has given me a whole different perspective on life. Each of these activities I have chosen for a specific reason, usually because
I enjoy the interaction with the other people involved and believe in the outcome and results.

This brings me back to my first paragraph where I shared with the reader my advice about choosing to do what inspires you. When you do this, it is not work, but fun. Choose wisely and when we leave this world, we can look back and say, "Job well done."

\section{Declarations}

Conflict of interest The author declares that they have no competing interests.

\section{Reference}

1. Proctor DD. Just do the best you can. Dig Dis Sci 2021.

Publisher's Note Springer Nature remains neutral with regard to jurisdictional claims in published maps and institutional affiliations. 